\title{
Selected Topics on Research Challenges in Information Science: Editorial Introduction to Issue 17 of CSIMQ
}

\author{
Benedicte Le Grand ${ }^{*}$ and Rebecca Deneckère \\ University of Paris1 Panthéon-Sorbonne, 75013, France \\ benedicte.le-grand@univ-paris1.fr, rebecca.deneckere@univ-paris1.fr
}

This thematic issue of the Complex Systems Informatics and Modeling Quarterly journal is dedicated to Information Science. We selected the best papers presented at the 12th edition of the International IEEE Conference on Research Challenges in Information Science (RCIS'2018) and invited their authors to submit extended versions of their articles [1], [2]. The articles presented in this thematic issue contain at least $30 \%$ new material compared to the initial papers.

The RCIS conference covers a wide spectrum of topics in the information science field: information search and discovery, requirement engineering, product lines, smart cities and Internet of Things, business processes, recommendation and prediction, security, social computing and Social Network Analysis, Human-Computer Interaction and systems engineering.

After an additional reviewing process, the articles which have been finally selected present contributions of different types to the field of information science: models, architectures, frameworks, and surveys.

The first paper of this thematic issue is entitled "Smart Data for Genomic Information Systems: the SILE Method", by Ana León Palacio and Óscar Pastor López. It shows how conceptual models can be used to move from a big data to a smart data perspective, and help extracting meaningful and reliable gene-disease relationships from a huge amount of genomic data.

The second paper, "Time-Dependent Influence Measurement in Citation Networks", by Monika Ewa Rakoczy, Amel Bouzeghoub, Alda Gancarski and Katarzyna Wegrzyn-Wolska, also aims at extracting information from data. The authors contribute to Social Network Analysis, by presenting an original model to evaluate the influence of research communities (such as conferences and journals) and help researchers find influential places to publish.

The third paper is entitled "Enabling Responsible Online Gambling by Real-time Persuasive Technologies", and has been written by George Drosatos, Fotis Nalbadis, Emily Arden-Close, Victoria Baines, Elvira Bolat, Laura Vuillier, Theodoros Kostoulas, Marcin Budka, Sonia Wasowska, Maris Bonello, Jamie Brown, Tessa Corner, John McAlaney, Keith Phalp, and Raian Ali. The authors present a conceptual architecture that results from a multi-disciplinary study of online gamblers' behavior. Their goal is to build more proactive and intelligent online gambling

\footnotetext{
* Corresponding author

(C) 2018 Benedicte Le Grand et al. This is an open access article licensed under the Creative Commons Attribution License (http://creativecommons.org/licenses/by/4.0).
}

Reference: B. Le Grand and R. Deneckère, "Selected Topics on Research Challenges in Information Science: Editorial Introduction to Issue 17 of CSIMQ," Complex Systems Informatics and Modeling Quarterly, CSIMQ, no. 17, pp. I-II, 2018. Available: https://doi.org/10.7250/csimq.2018-17.00 
services. In this paper, the authors present the challenges of developing a software-assisted intervention, persuasion and emotion regulation technology.

While the three first papers of this thematic issue propose new models and architectures, we have also selected a paper dedicated to the enhancement of an existing framework. Indeed, the first idea is essential in any research work, but it is important to help users take up the proposed solution.

The fourth paper, entitled "Evaluating company's readiness for adopting product line engineering: a second evaluation round", by Luisa Rincón, Raúl Mazo, and Camille Salinesi, aims at supporting decision-makers in taking informed decision in favor or against the adoption of a product line approach. To this end, the authors present the 2 nd version of a framework designed to evaluate organizations' motivation and preparation for adopting product lines.

Finally, we selected a paper which investigates why particular principles sometimes face obstacles during enterprise architecture development phase.

In the fifth paper, "The Role of Top Management Commitment in Enterprise Architecture Development in Governmental Organizations", Negin Banaeianjahromi used the Grounded Theory Methodology to understand the problems that occurred in 9 governmental organizations in Iran when they attempted to develop an Enterprise Architecture strategy.

We are grateful to all the people who have contributed to this thematic issue: the RCIS program board and program committee for the review of all papers, and in particular the reviewers of the papers invited to this thematic issue for their additional work. We also warmly thank Marite Kirikova for her support throughout the whole edition process.

We hope you will enjoy reading these articles, which represent a sample of challenges and contributions in the field of Information Science.

\section{References}

[1] Website of the 12th edition of the International IEEE Conference on Research Challenges in Information Science (RCIS'2018). Available: http://www.rcis-conf.com/rcis2018/

[2] 2018 12th International Conference on Research Challenges in Information Science (RCIS 2018): Proceedings of a meeting held 29-31 May 2018, Nantes, France, Institute of Electrical and Electronics Engineers ( IEEE ), 2018. 